\title{
Associated Morbidity in Screened and Diagnosed Breast Cancer Patients: A Retrospective Study
}

\section{Diane B-I, Birgit C and Serge $\mathbf{R}^{*}$}

Department of Obstetrics and Gynecology, Isala Breast

Unit and Prevention Centre, University Hospital

Saint-Pierre (Université Libre de Bruxelles and Vrije

Universiteit Brussel), Brussels, Belgium

*Corresponding author: Serge Rozenberg,

Department of Obstetrics and Gynecology, Isala Breast

Unit and Prevention Centre, University Hospital

Saint-Pierre (Université Libre de Bruxelles and Vrije

Universiteit Brussel), Brussels, Belgium

Received: J une 25, 2021; Accepted: July 09, 2021;

Published: July 16, 2021

\begin{abstract}
Introduction: Breast Cancer (BC) screening has been associated with reduced mortality and morbidity. This study compares tumor characteristics and treatment morbidity in screened versus diagnosed women.

Materials and Methods: This retrospective study, conducted between 2010 and 2013 , included 666 BC screened or diagnosed patients. We compared patients and tumors characteristics and received treatments. We also analyzed the results after excluding patients at risk of $B C$ and conducted a multivariate analysis to assess odds ratios (OR).

Results: Screened women had smaller tumors (16.5 vs. $22.6 \mathrm{~mm}, \mathrm{p}<0.001)$, of lowe grade $(p<0.001)$ with a lower Proliferation Index $(P I)(p<0.001)$ than diagnosed women. Screened women were more frequently treated using conservative surgery $(82.8 \% \mathrm{vs}$. $59.7 \%, p<0.001)$, needed less often axillary dissection (15.1\% vs. 35.4\%, p<0.001) and less often chemotherapy $(20.8 \%$ vs. $48.3 \%$ p $<0.001)$ than diagnosed women. In the multivariate analysis after adjustment for age and BC history, diagnosed women had increased (OR: 4.79, 95\% IC: $3.19-7.18$ ) risk to be administered chemotherapy and to undergo axillary dissection (OR: 4.18, 95\% IC: 1.56-11.17) than screened women.
\end{abstract}

Conclusion: Patients should be informed about the benefits in terms of morbidity that screening confers to them.

Keywords: Breast cancer; Screening; Morbidity; Treatments

\section{Introduction}

While Breast Cancer (BC) remains the most frequent cancer in women, its mortality decreased in most high-income countries during the last decade [1]. This is generally attributed to treatment improvement and screening, resulting in earlier diagnosis and better prognosis, although the latter has been highly debated [2,3]. Indeed, while some studies estimated that organized screening contributes to a twenty percent reduction in BC mortality $[4,5]$, others challenged these data and reported increased harm due to a 30-50 \% BC overdiagnosis resulting from screening [6].

Both "true BC" and "over-diagnosed cancer" may be associated with considerable physical and psychological morbidity $[7,8]$. Nevertheless, screening is supposed to improve quality of life due to the early stage of the cancer and the associated less aggressive treatment than in symptomatically diagnosed cancers. This may theoretically be true, but has not often be studied [9]. In this retrospective analysis, we quantify the morbidity due to $\mathrm{BC}$ and its treatments in "Screened Women" (SW) as compared to that of symptomatic women, defined as "Clinically Diagnosed Women" (CDW). We further quantified the $\mathrm{BC}$ morbidity in diagnosed and screened women, after having excluded women at risk of breast cancer due to a family history.

\section{Materials and Methods}

\section{Study design: retrospective cohort study}

Patients selection: We analyzed systematically all the data of patients diagnosed with BC from January 2010 and December 2013 $(\mathrm{n}=669)$ in the C.H.U Saint-Pierre, a community and university hospital situated downtown Brussels, and treating a multicultural population.
Screened tumors were discovered by mammography in asymptomatic women who were invited to be screened by the Brussels region ("Mammotest program") or were send by their physician for opportunistic screening. The uptake of organized screening is rather low in Brussels, (and this is in part due to the complex administrative bilingual situation of the Brussels district). That is why many women are still send by their physicians for opportunistic screening every two years (as for organized screening) or every year when they have a first-degree family history of breast cancer.

Screened women under 50 and over 69 years-old had opportunistic screening given the fact that organized screening does not apply to them, although more and more physicians and opinion leaders consider that there is a place for screening at those ages.

Clinically diagnosed tumors included symptoms such as feeling a mass, an axillary adenopathy, mammary discharge, pain, skin retraction, ulceration, pleural effusion or symptoms related to a metastasis. We excluded male patients and those fortuitously discovered (during breast reduction) $(\mathrm{n}=3)$.

We collected data about the date of BC detection, mode of detection and tumors characteristics. These data were collected systematically and are forwarded to the Belgian Cancer registry.

\section{Tumors' characteristics}

We included stage, size, whether there was extensive disease (node and metastasis), the Elston-Ellis histopronostic grade (ranging from I to III), whether the tumor was in situ or invasive, lobular or ductal, the expression of estrogen and progesterone receptors, the proliferation index (classified as low when the Ki67 $<15 \%$ and high when Ki67>15\%) and the presence of HER2 gene amplification. 
Table 1: Characteristics of screened and diagnosed tumors before excluding at risk patients (Global analysis).

\begin{tabular}{|c|c|c|c|}
\hline Characteristics & Screened Tumors $(n=279)$ & Clinically Diagnosed Tumors $(n=387)$ & $p$ \\
\hline \multicolumn{4}{|l|}{ Women's Characteristics } \\
\hline Mean age (years-old) [SD] & $57[11]$ & 59 [15] & 0.196 \\
\hline$\%$ with personal and/or familial BC history & 34.6 & 37.7 & 0.436 \\
\hline \multicolumn{4}{|l|}{ Tumors' Characteristics } \\
\hline Mean size $(\mathrm{mm})[\mathrm{SD}]$ & $16,46[15,40]$ & $22,62[19,27]$ & $<0.001$ \\
\hline Median size $(\mathrm{mm})$ [IQR] & $12[9]$ & $17[13]$ & \\
\hline \multicolumn{4}{|l|}{ Grade (\%): } \\
\hline > 1 & 25.4 & 16 & \\
\hline$\vdash 2$ & 45.9 & 45.7 & 0.001 \\
\hline$\checkmark 3$ & 19.7 & 29.7 & \\
\hline$\%$ invasive carcinoma & 74.2 & 87.4 & $<0.001$ \\
\hline$\%$ in situ carcinoma & 18.3 & 7.2 & $<0.001$ \\
\hline$\%$ ductal carcinoma & 79.9 & 83.5 & 0.48 \\
\hline \% lobular carcinoma & 18,3 & 15,0 & \\
\hline$\%$ node positive & 5.7 & 19.7 & $<0.001$ \\
\hline \% ER positive & 79.9 & 71.8 & 0.017 \\
\hline$\%$ PR positive & 74.2 & 66.9 & 0.043 \\
\hline Ki $67>15 \%$ & 13.6 & 28.7 & $<0.001$ \\
\hline HER2 gene amplification (\%) & 4.7 & 12.1 & 0.005 \\
\hline Metastasis (\%) & 2.9 & 14 & $<0.001$ \\
\hline \multicolumn{4}{|l|}{ Treatments' Characteristics } \\
\hline Lumpectomies (\%) & 82.8 & 59.7 & $<0.001$ \\
\hline Mastectomies (\%) & 15.8 & 29.5 & $<0.001$ \\
\hline Removal sentinel node (\%) & 75.6 & 44.7 & $<0.001$ \\
\hline Axillary LND (\%) & 15.1 & 35.4 & $<0.001$ \\
\hline Chemotherapy (\%) & 20.8 & 48.3 & $<0.001$ \\
\hline Hormonotherapy (\%) & 77.1 & 62.5 & $<0.001$ \\
\hline Radiotherapy (\%) & 83.5 & 74.9 & 0.008 \\
\hline
\end{tabular}

SNL: Sentinel Node; LND: Lymph Node.

Treatment characteristics: The following information about treatment was collected: type of surgery (lumpectomy, mastectomy, axillary lymph node dissection, removal of the sentinel node), radiotherapy, neo-adjuvant chemotherapy or chemotherapy postsurgery, use of hormone-therapy and immunotherapy.

Outcomes: In particular, we considered as surrogate markers of morbidity: having a mastectomy versus a lumpectomy, an axillary Lymph Node Dissection (LND) versus the removal of the sentinel node and undergoing chemotherapy or not.

\section{Power analysis}

We calculated that using a power of $80 \%$ (type II error) and type I error of $5 \%$ and hypothesizing a $50 \%$ reduction of needed chemotherapy $(\mathrm{p}$ (diagnosed $)=0.50 v s$. $\mathrm{p}($ screened $)=0.25 ; \mathrm{n}=55)$, of mastectomy $(\mathrm{p}($ diagnosed $)=0.4 v s . \mathrm{p}($ screened $)=0.2, \mathrm{n}=79)$ less than 100 patients were needed.

\section{Statistical analyses}

Groups were compared using Chi-squared test, Fisher's exact test for small numbers and $t$ tests. The first analysis compared tumors' characteristics and treatments between all screened and clinically diagnosed women (Table 1). Characteristics were expressed in mean + standard deviation or median (IQR) when there were continuous and in percentage when they were categorical. In order to reduce the risk of bias, we conducted a second analysis, excluding women with relevant $\mathrm{BC}$ risk factors (such as personal and/or $1^{\text {st }}, 2^{\text {nd }}$ or $3^{\text {rd }}$ degree family $\mathrm{BC}$ history, or genetic $\mathrm{BC}$ predisposition) and stratified these analyses by age classes (40-49, 50-69 and 70-75 years old) (Figure 1).

A multivariate analysis was also conducted to examine the effect of the screening versus clinical diagnosis on having a mastectomy versus a lumpectomy, an axillary Lymph Node Dissection (LND) versus the removal of the sentinel node and undergoing chemotherapy or not. A p-value $\leq 0.05$ was considered as statistically significant. All analyses were conducted using SPSS 25.

The study was approved par the local ethical committee $\left(\mathrm{N}^{\circ}\right.$ O.M.007). 


\section{Results}

Characteristics of patients, tumors and received treatments (Global analysis of screened versus diagnosed patients Table 1).

From January 2010 to December 2013, 666 BC have been diagnosed in patients aged 21 to 96 years old. More than a third of them had a personal or family BC history.

Screened patients who had BC, had tumors that were less aggressive than $\mathrm{BC}$ patients diagnosed for symptomatic tumors. For instance, screened women had tumors of lower grade $(\mathrm{p}<0.001)$, lower stage and had three times less often involved nodes (19.7\% vs. $5.7 \%)(\mathrm{p}<0.001)$ than diagnosed women. Screened women were also more likely to have tumors expressing hormonal receptors and had twice less often tumors overexpressing HER2 receptors (Table 1).

Similarly, screened women had twice less often mastectomies ( $15.8 \%$ vs. $29.5 \%, \mathrm{p}<0.001)$ and chemotherapy $(20.8 \%$ vs. $48.3 \%$ $\mathrm{p}<0.001)$, but more often sentinel node removal $(75.6 \%$ vs. $44.7 \%$, $\mathrm{p}<0.001)$, radiotherapy and hormone-therapy than diagnosed women (Table 1).

Characteristics of tumors and treatments after exclusion of women with a personal or familial history of BC, stratified by age (Figure 1, Table 2).

After stratification by age (in the three studied age groups) and exclusion of women with a personal or family BC history, similar results were observed than in the global analysis. Screened patients of all ages had tumors that were less advances and had lower proliferation indices than diagnosed women (Table 2). Screened women aged 40-49 and 50-69 had three times more often in situ tumors, less often-invaded nodes and less often HER2 gene overexpression than diagnosed women (Table 2). Screened women aged 50-69 and 70-75 had smaller tumors than diagnosed women $(\mathrm{p}<0.001$ and $\mathrm{p}<0.002)$. After stratification, no significant difference between groups was observed concerning expression of hormonal receptors.

Similarly, screened women, regardless of age, had more often sentinel node removal. Screened women aged 50 -69 were more often treated by lumpectomy $(81.7 \%$ versus $63.1 \%(\mathrm{p}<0.001)$ and less often by mastectomy (17.8\% versus $32.4 \%$ ) than diagnosed women. Diagnosed women aged from 40-49 and 50-69 years old were treated more often using chemotherapy than screened women (respectively $65.2 \%$ vs. $31.6 \%$ and $49.7 \%$ vs. $18.3 \%, \mathrm{p}<0.001$ ).

\section{Multivariate analysis}

Using a multivariate analysis, after adjustment for age and $\mathrm{BC}$ history, diagnosed $\mathrm{BC}$ patients were twice more likely to be treated by mastectomy than by lumpectomy (OR: $2.61,95 \%$ IC: $1.72-3.95)$, four times more likely to have an axillary lymph node dissection rather than a sentinel node removal (OR: 4.46, 95\% IC: 2.88-6.91) and five times more like to be treated by chemotherapy (OR: 4.79 , 95\% IC: 3.19-7.18) as compared to screened women.

On the other hand, no significant differences were observed concerning treatments between screened and clinically diagnosed women, who were older than 70 years of age.

\section{Discussion}

\section{The advantages and risks of BC screening have been much debated $[2,4,9]$}

In brief, the optimal way to compare mortality and morbidity in screened and unscreened groups requires randomized trials with large uptakes and a long follow-up. Nevertheless, technology evolves with time, which means that long-term evaluation of imaging technics in term of accuracy, precision or irradiation is difficult since these will

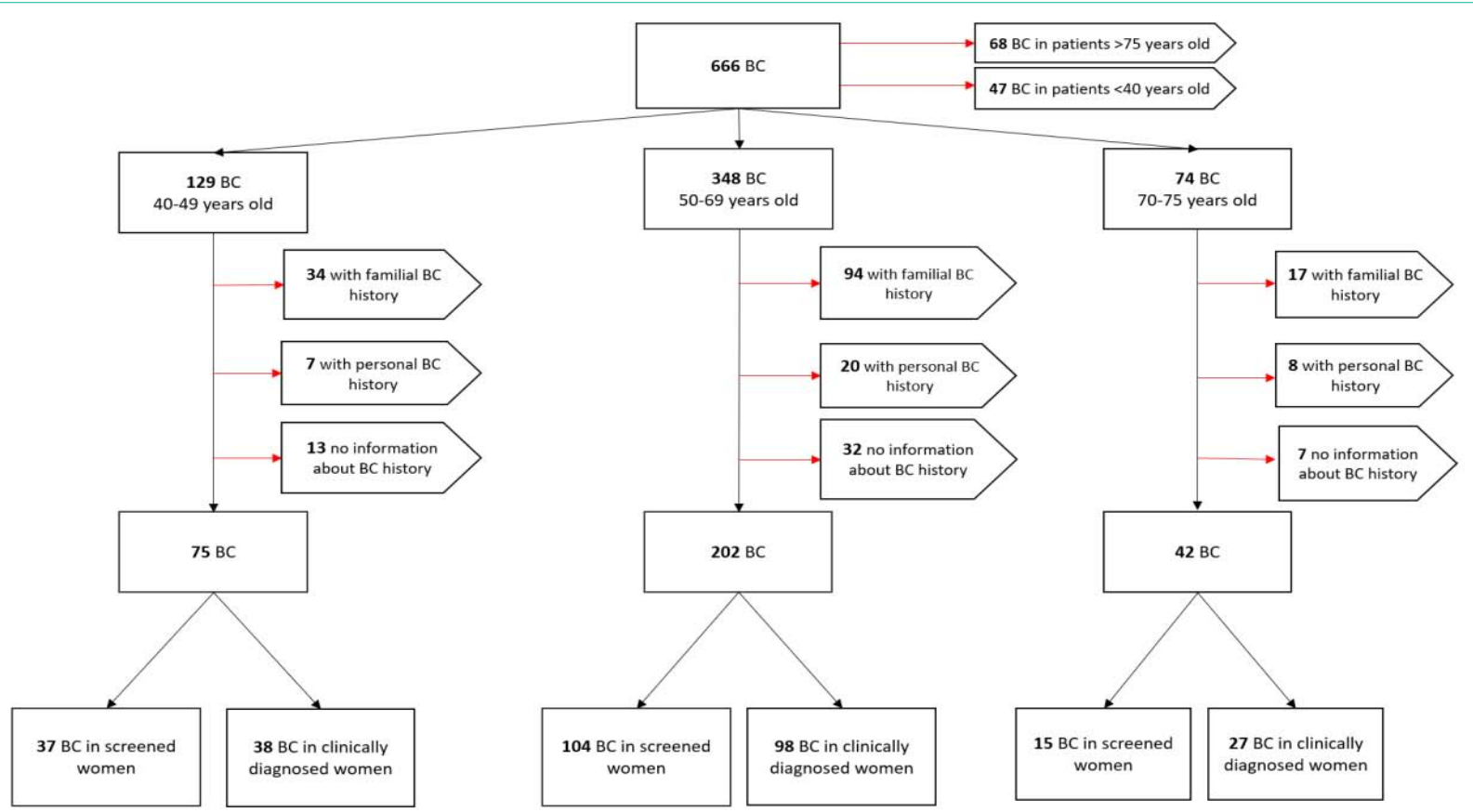

Figure 1: Flow chart of the patients' selection: Patients were divided in 3 groups according to their age. In a second analysis, we excluded patients with a family or personal BC history. 
Table 2: Characteristics of screened and diagnosed tumors in patients without familial or personal BC history, stratified by age and by mode of presentation.

\begin{tabular}{|c|c|c|c|c|c|c|c|c|c|}
\hline \multirow[t]{2}{*}{ Characteristics } & \multicolumn{3}{|c|}{ 40-49 Years-Old } & \multicolumn{3}{|c|}{ 50-69 Years-Old } & \multicolumn{3}{|c|}{ 70-75 Years-Old } \\
\hline & $\begin{array}{c}\text { Screened } \\
\text { tumors } \\
(n=37)\end{array}$ & $\begin{array}{l}\text { Clinically diagnosed } \\
\text { tumors }(n=38)\end{array}$ & $p$ & $\begin{array}{c}\text { Screened } \\
\text { tumors } \\
(n=104)\end{array}$ & $\begin{array}{l}\text { Clinically diagnosed } \\
\text { tumors }(n=98)\end{array}$ & $p$ & $\begin{array}{c}\text { Screened } \\
\text { tumors } \\
(n=15)\end{array}$ & $\begin{array}{c}\text { Clinically diagnosed } \\
\text { tumors }(n=27)\end{array}$ & $p$ \\
\hline \multicolumn{10}{|l|}{ Stage T (\%) } \\
\hline Tis & 23.3 & 7.2 & $<0.001$ & 18.9 & 5.6 & $<0.001$ & 0 & 10.6 & $<0.001$ \\
\hline T1a-T1b & 33.3 & 14.5 & II & 33.7 & 16.8 & II & 63 & 12.8 & II \\
\hline $\mathrm{T} 1 \mathrm{c}$ & 28.3 & 30.4 & II & 29.6 & 31.8 & II & 22.2 & 29.8 & II \\
\hline $\mathrm{T} 2$ & 8.3 & 37.7 & II & 7.1 & 24 & II & 7.4 & 31.9 & II \\
\hline T3 & 1.7 & 4.3 & II & 0.6 & 7.3 & II & 0 & 6.4 & II \\
\hline $\mathrm{T} 4$ & 0 & 4.3 & II & 0.6 & 6.1 & II & 3.7 & 6.4 & II \\
\hline \multicolumn{10}{|l|}{ Stage N (\%) } \\
\hline No & 83.3 & 72.5 & 0.029 & 76.3 & 68.7 & 0.036 & 81.5 & 68.1 & 0.359 \\
\hline $\mathrm{N} 1$ & 1.7 & 15.9 & II & 6.5 & 16.2 & II & 7.4 & 19.1 & II \\
\hline N2 & 0 & 0 & II & 0 & 0.6 & II & 0 & 0 & II \\
\hline N3 & 0 & 1.4 & II & 0 & 0.6 & II & 0 & 0 & II \\
\hline \multicolumn{10}{|l|}{ Stage M (\%) } \\
\hline M1 & 0 & 10.1 & 0.04 & 0 & 3.9 & 0.027 & 3.7 & 12.8 & 0.436 \\
\hline \multicolumn{10}{|l|}{$\begin{array}{l}\text { Other Tumors' } \\
\text { Characteristics }\end{array}$} \\
\hline Mean size $(\mathrm{mm})$ & 18.34 & 18.05 & 0.703 & 16.27 & 22.76 & 0.001 & 9,87 & 25,42 & 0,002 \\
\hline [SD] & [15.29] & [14.22] & & [16.13] & [18.21] & & {$[5,64]$} & {$[17,75]$} & \\
\hline$\%$ ductal tumors & 91.7 & 81.6 & 0,205 & 77.9 & 83.7 & 0,298 & 73.3 & 77.8 & 0,746 \\
\hline$\%$ lobular tumors & 8.3 & 15.8 & 0,327 & 20.2 & 14.3 & 0,268 & 26.7 & 22.2 & 0,746 \\
\hline$\%$ ER positive & 80 & 72.5 & 0.158 & 79.3 & 72.6 & 0.146 & 85.2 & 66 & 0.073 \\
\hline \% PR positive & 73.3 & 65.2 & 0.209 & 75.7 & 67 & 0.073 & 74.1 & 63.8 & 0.365 \\
\hline$\%$ with Ki $67>15 \%$ & 15 & 30.4 & 0.012 & 13.6 & 26.8 & 0.022 & 7.4 & 29.8 & 0.02 \\
\hline $\begin{array}{c}\text { HER2 gene amplification } \\
(\%)\end{array}$ & 3.3 & 14.5 & 0.003 & 4.1 & 11.7 & $<0.001$ & 11.1 & 2.1 & 0.078 \\
\hline \multicolumn{10}{|l|}{ Grade (\%): } \\
\hline • 1 & 32.4 & 21.1 & & 26.9 & 15.3 & & 26.7 & 25.9 & \\
\hline$\checkmark 2$ & 40.5 & 36.8 & 0.363 & 45.2 & 51 & 0.038 & 60 & 37 & 0.302 \\
\hline 13 & 21.6 & 34.2 & & 14.4 & 25.5 & & 6.7 & 22.2 & \\
\hline Metastasis (\%) & 1.7 & 14.5 & 0.009 & 3 & 12.3 & 0.003 & 0 & 17 & 0.023 \\
\hline \multicolumn{10}{|l|}{$\begin{array}{l}\text { Treatments' } \\
\text { Characteristics }\end{array}$} \\
\hline Lumpectomies (\%) & 85.0 & 72.5 & 0.085 & 81.7 & 63.1 & $<0.001$ & 92.6 & 57.4 & 0.001 \\
\hline Mastectomies (\%) & 13.3 & 23.2 & 0.151 & 17.8 & 32.4 & 0.002 & 7.4 & 25.5 & 0.055 \\
\hline Removal SNL node (\%) & 75 & 47.8 & 0.002 & 75.1 & 48.3 & $<0.001$ & 81.5 & 52.2 & 0.012 \\
\hline Axillary LND (\%) & 13.3 & 42 & $<0.001$ & 16 & 38.8 & $<0.001$ & 11.1 & 17.4 & 0.469 \\
\hline Chemotherapy (\%) & 31.6 & 65.2 & $<0.001$ & 18.3 & 49.7 & $<0.001$ & 18.5 & 27.7 & 0.378 \\
\hline Hormonetherapy (\%) & 76.7 & 53.6 & 0.016 & 79.3 & 65.9 & 0.005 & 77.8 & 57.4 & 0.078 \\
\hline Radiotherapy (\%) & 86.7 & 84.1 & 0.677 & 82.2 & 82.1 & 0.976 & 88.9 & 59.6 & 0.008 \\
\hline
\end{tabular}

SNL: Sentinel Node; LND: Lymph Node.

have improved in the meantime.

Most randomized trials and meta-analysis of these trials with long follow-up estimated that screening provides a $20 \%$ reduction in breast cancer mortality. Nevertheless, several uncertainties exist [10]. The major recognized harm of screening is overdiagnosis, i.e., a cancer that has been discovered by screening, but that would not otherwise have come to attention in the woman's lifetime. Even more, uncertainties exist about the magnitude of over-diagnosis than about the mortality reduction, but many experts have estimated the risk of overdiagnosis to be in the range of 10-20\% [10].

The subject is therefore complex, and this study does not have the ambition to provide an answer to that question. Nevertheless, 
Table 3: Likelihood of received treatments, according to the mode of BC detection (screened or clinically diagnosed): Binary logistic regression.

\begin{tabular}{|c|c|c|c|c|c|c|}
\hline \multirow{2}{*}{ Age Groups } & \multicolumn{2}{|c|}{ Lumpectomy vs. Mastectomy } & \multicolumn{2}{|c|}{ SNL Node Removal vs. Axillary LND } & \multicolumn{2}{|c|}{ Chemotherapy vs. No Chemotherapy } \\
\hline & $p$ & OR (IC 95\%) & $p$ & OR (IC 95\%) & $p$ & OR (IC 95\%) \\
\hline All & $<0.001$ & $2.61(1.72-3.95)$ & $<0.001$ & $4.46(2.88-6.91)$ & $<0.001$ & $4.79(3.19-7,18)$ \\
\hline $40-49 y-0$ & 0.454 & & 0.004 & $4.18(1.56-11.17)$ & $<0.001$ & $4.47(1.97-10.15)$ \\
\hline $50-69$ y-o & 0.002 & $2.63(1.53-4.54)$ & $<0.001$ & $4.64(2.62-8.21)$ & $<0.001$ & $5.27(3.07-9.04)$ \\
\hline $70-75 y-0$ & 0.132 & & 0.085 & & 0.148 & \\
\hline
\end{tabular}

SNL: Sentinel Node; LND: Lymph Node.

we aimed to analyze in our daily practice the tumor and treatment characteristics of screened patients versus symptomatically diagnosed patients. Our study is different from some others because it provides additional information on patients $\mathrm{BC}$ history and, therefore, allows us to assess women at lower risk of BC.

We observed that more than one-third of patients had at least one family and/or personal history of BC. (34.6\% among SW and 37.7\% among CDW).

After excluding women with a family or personal history of $\mathrm{BC}$, we observed that screened women younger than 50 , were more likely to be treated by sentinel node removal and less likely to be administered chemotherapy than symptomatic diagnosed women. On the other hand, there was no difference between both groups regarding the proportion of conservative surgery or the average tumor's size, contrary to other studies reporting smaller and lower in grade tumors in screened than in clinically diagnosed tumors [1114]. It should be noted that, in the age group 40-49 screening is not advocated by most guidelines or the Belgian authorities.

Patients aged from 50-69, who had been screened, as suggested by Belgian guidelines, had more often conservative surgery than women whose tumor had been diagnosed due to symptoms $(83 \%$ vs. $60 \%$ ). These figures are higher than those observed by Barth et al. (respectively 56\% and 32\% of conservative treatments) [9]. Moreover, in our series, screened women had four times more often sentinel node excision instead of axillary node dissection and five times less often chemotherapy than symptomatically diagnosed women. This results in fewer side effects such as arm stiffness, edema, pain and impaired movements, lower risk of neurotoxicity, cardiomyopathy and thromboembolism [15-18].

On the other hand, screened patients older than 70, had not been treated with less aggressive treatments than diagnosed women.

For patients to be able to make an enlightened choice on participating to systematic screening, a clear information needs to be provided. Nowadays, women are informed about the harms of screening such as false positives and over-diagnoses, as well as the risk of false negatives, pain, discomfort, and exposure to increased radiation [19].

Motivation to be screened or not, can result from information about the number of patients needed to be screened (NNS) to prevent one breast cancer death, which, based on a meta-analysis, ranges between 377 for women aged 60-69 years and 1339 for those aged 5059 and 1904 for those aged 39-49 years [20]. Knowing that screened cancers are associated with a much-reduced risk of morbid treatment, as compared to diagnosed cancers, may also motivate women to be screened.
The morbidity following treatment of a $\mathrm{BC}$ is especially feared for breast surgery, axillary surgery and chemotherapy. In our study, we observed that screened women were between twice and five times more likely to be treated by less harmful treatments than diagnosed women.

Our study is hampered by several limitations: we have not addressed the problem of over-diagnosis in this study, and we cannot rule out that some of the screened tumors with a better prognosis were actually over-diagnosed tumors [21,22]. Unfortunately, currently, in our daily practice, we are unable to distinguish over-diagnosed tumors from tumors that need to be treated [23].

Moreover, we were unable to distinguish women screened opportunistically from those screened through organized screening. We were also unable to assess whether women who had opportunistic screening had had an organized screening in the past or vice versa. The ideal comparison should have been performed between women participating in the organized screening programme, and those who were diagnosed. We were unable to do this, as stated before. This would have result in analyzing even smaller groups, which precludes drawing conclusions. But even in such a setting, differences between screened and unscreened women exist, as it has been observed that screened women are often more aware of their health and use more often menopause hormone therapy [24,25].

Our outcomes included surrogate markers of morbidity: having a mastectomy versus a lumpectomy, an axillary Lymph Node Dissection (LND) versus the removal of the sentinel node and undergoing chemotherapy or not. However, we did not include investigations, such which may also add stress and discomfort, false positive mammography and unnecessary biopsies, false-negative mammography, leading to delayed diagnosis, nor re-operation rates. Women with extremely dense breast tissue have an increased risk of breast cancer, and their cancers are also less likely to be detected on mammography, leading to an increased risk of Interval cancers. This risk may be reduced by supplemental MRI screening [24].

In this study, we were unable to take into consideration this source of bias, as we did not analyze either the mammographic density of screened or diagnosed women.

\section{Conclusion}

In conclusion, most expert groups encourage shared decisionmaking with women [27]. In this respect, our study suggest that, although we cannot rule out that screened women had more often over-diagnosed tumors, they underwent more often less aggressive treatments that were associated with less side effects and less morbidity. Patients should be informed about the risk of screening but also the possible associated advantages in terms of morbidity. The 
current Belgian screening program advertises on its website "being screened reduces the mortality by $20 \%$. Concerning morbidity, there are only a few words: screening is associated with "lighter treatment". In addition, it does not mention risks associated with screening [28]. The current leaflets mention, however, overdiagnosis risk, and reduced mortality but do not mention possible associated advantages in terms of morbidity associated with screening [29].

\section{Contributors}

BC developed the idea of the study. DB collected the data, analyzed them and wrote the first draft. All the authors corrected the manuscript and approved the manuscript.

\section{Conflict of Interest}

The manuscript was used in a previous form as a medical student thesis by DB.

\section{References}

1. Oeffinger KC, Fontham ETH, Etzioni R, Herzig A, Michaelson JS, Shih Y-CT, et al. Breast Cancer Screening for Women at Average Risk: 2015 Guideline Update From the American Cancer Society. JAMA. 2015; 314: 1599-1614

2. Autier $\mathrm{P}$, Boniol $\mathrm{M}$. Mammography screening: $\mathrm{A}$ major issue in medicine. Eur J Cancer Oxf Engl. 2018; 90: 34-62.

3. Depypere H, Desreux J, Pérez-López FR, Ceausu I, Erel CT, Lambrinoudak I, et al; EMAS. EMAS position statement: individualized breast cance screening versus population-based mammography screening programmes. Maturitas. 2014; 79: 481-486.

4. Marmot MG, Altman DG, Cameron DA, Dewar JA, Thompson SG, Wilcox M The benefits and harms of breast cancer screening: an independent review. Br J Cancer. 2013; 108: 2205-2240.

5. Gøtzsche PC, Jørgensen KJ. Screening for breast cancer with mammography. Cochrane Database Syst Rev. 2013; 2013: CD001877.

6. Bleyer A, Welch HG. Effect of Three Decades of Screening Mammography on Breast-Cancer Incidence. N Engl J Med. 2012; 367: 1998-2005.

7. Leung JWT. Screening mammography reduces morbidity of breast cancer treatment. AJR Am J Roentgenol. 2005; 184: 1508-1509.

8. Paesmans M, Ameye L, Moreau M, Rozenberg S. Breast cancer screening in the older woman: an effective way to reduce mortality? Maturitas. 2010; 66: 263-267.

9. Brennan M, Houssami N. Discussing the benefits and harms of screening mammography. Maturitas. 2016; 92: 150-153.

10. Independent UK Panel on Breast Cancer Screening. The benefits and harms of breast cancer screening: an independent review. Lancet. 2012; 380: 17781786.

11. Barth RJ, Gibson GR, Carney PA, Mott LA, Becher RD, Poplack SP Detection of breast cancer on screening mammography allows patients to be treated with less-toxic therapy. AJR Am J Roentgenol. 2005; 184: 324-329.

12. Cowan WK, Kelly P, Sawan A, Cunliffe WJ, Henry L, Higgs MJ, et al. The pathological and biological nature of screen-detected breast carcinomas: a morphological and immunohistochemical study. J Pathol. 1997; 182: 29-35.
13. Spillane AJ, Kennedy CW, Gillett DJ, Carmalt HL, Janu NC, Rickard MT, et al. Screen-detected breast cancer compared to symptomatic presentation: an analysis of surgical treatment and end-points of effective mammographic screening. ANZ J Surg. 2001; 71: 398-402.

14. Chuwa EWL, Yeo AWY, Koong HN, Wong CY, Yong WS, Tan PH, et al. Early detection of breast cancer through population-based mammographic screening in Asian women: a comparison study between screen-detected and symptomatic breast cancers. Breast J. 2009; 15: 133-139.

15. Azim HA, de Azambuja E, Colozza M, Bines J, Piccart MJ. Long-term toxic effects of adjuvant chemotherapy in breast cancer. Ann Oncol. 2011; 22: 1939-1947.

16. Cameron AC, Touyz RM, Lang NN. Vascular Complications of Cancer Chemotherapy. Can J Cardiol. 2016; 32: 852-862.

17. Swenson KK, Nissen MJ, Ceronsky C, Swenson L, Lee MW, Tuttle TM Comparison of side effects between sentinel lymph node and axillary lymph node dissection for breast cancer. Ann Surg Oncol. 2002; 9: 745-753.

18. Brar P, Jain S, Singh I. Complications of Axillary Lymph Node Dissection in Treatment of Early Breast Cancer: A Comparison of MRM and BCS. Indian J Surg Oncol. 2011; 2: 126-132.

19. Shieh Y, Eklund M, Sawaya GF, Black WC, Kramer BS, Esserman LJ. Population-based screening for cancer: hope and hype. Nat Rev Clin Oncol. 2016; 13: 550-565.

20. Nelson HD, Tyne K, Naik A, et al. Screening for breast cancer: an update for the U.S. Preventive Services Task Force. Ann Intern Med. 2009; 151: 727 737, W237-242.

21. Brouckaert O, Schoneveld A, Truyers C, Kellen E, Van Ongeval C, Vergote I, et al. Breast cancer phenotype, nodal status and palpability may be useful in the detection of over diagnosed screening-detected breast cancers. Ann Oncol. 2013; 24: 1847-1852.

22. Dawson SJ, Duffy SW, Blows FM, Driver KE, Provenzano E, LeQuesne J, et al. Molecular characteristics of screen-detected vs. symptomatic breast cancers and their impact on survival. Br J Cancer. 2009; 101: 1338-1344.

23. Løberg M, Lousdal ML, Bretthauer M, Kalager M. Benefits and harms of mammography screening. Breast Cancer Res BCR. 2015; 17: 63.

24. Heinig M, Schwarz S, Haug U. Self-selection for mammography screening according to use of hormone replacement therapy: A systematic literature review. Cancer Epidemiol. 2021; 71: 101812

25. Baird J, Yogeswaran G, Oni G, Wilson EE. What can be done to encourage women from Black, Asian and minority ethnic backgrounds to attend breast screening? A qualitative synthesis of barriers and facilitators. Public Health. 2021; 190: 152-159.

26. Bakker MF, de Lange SV, Pijnappel RM, Mann RM, Peeters PHM, Monninkhof EM, et al; DENSE Trial Study Group. Supplemental MRI Screening for Women with Extremely Dense Breast Tissue. N Engl J Med. 2019; 381: 2091-2102.

27. Desreux J, Bleret V, Lifrange E. Should we individualize breast cancer screening? Maturitas. 2012; 73: 202-205.

28. BruPrev. Breast Cancer.

29. Une invitation à prendre soin de vous. Le Mammotest. 